\title{
Toll-Like Receptor 9-Dependent AMPK $\alpha$ Activation Occurs via TAK1 and Contributes to RhoA/ROCK Signaling and Actin Polymerization in Vascular Smooth Muscle Cells
}

\author{
Cameron G. McCarthy, Camilla F. Wenceslau, Safia Ogbi, Theodora Szasz, \\ and R. Clinton Webb
}

Department of Physiology, Augusta University, Augusta, Georgia

Received October 17, 2017; accepted January 17, 2018

\begin{abstract}
Traditionally, Toll-like receptor 9 (TLR9) signals through an MyD88-dependent cascade that results in proinflammatory gene transcription. Recently, it was reported that TLR9 also participates in a stress tolerance signaling cascade in nonimmune cells. In this noncanonical pathway, TLR9 binds to and inhibits sarcoplasmic/endoplasmic reticulum $\mathrm{Ca}^{2+}$-ATPase 2 (SERCA2), modulating intracellular calcium handling, and subsequently resulting in the activation of $5^{\prime}$-AMP-activated protein kinase $\alpha(\mathrm{AMPK} \alpha)$. We have previously reported that TLR9 causes increased contraction in isolated arteries; however, the mechanisms underlying this vascular dysfunction need to be further clarified. Therefore, we hypothesized that noncanonical TLR9 signaling was also present in vascular smooth muscle cells (VSMCs) and that it mediates enhanced contractile responses through SERCA2 inhibition. To test these hypotheses, aortic microsomes, aortic VSMCs, and isolated arteries from male Sprague-Dawley rats were incubated with
\end{abstract}

vehicle or TLR9 agonist (ODN2395). Despite clear AMPK $\alpha$ activation after treatment with ODN2395, SERCA2 activity was unaffected. Alternatively, ODN2395 caused the phosphorylation of $\mathrm{AMPK} \alpha$ via transforming growth factor $\beta$-activated kinase 1 (TAK1), a kinase involved in TLR9 inflammatory signaling. Downstream, we hypothesized that that TLR9 activation of AMPK $\alpha$ may be important in mediating actin cytoskeleton reorganization. ODN2395 significantly increased the filamentous-to-globular actin ratio, as well as indices of RhoA/Rho-associated protein kinase (ROCK) activation, with the latter being prevented by AMPK $\alpha$ inhibition. In conclusion, AMPK $\alpha$ phosphorylation after TLR9 activation in VSMCs appears to be an extension of traditional inflammatory signaling via TAK1, as opposed to SERCA2 inhibition and the noncanonical pathway. Nonetheless, TLR9-AMPK $\alpha$ signaling can mediate VSMC function via RhoA/ROCK activation and actin polymerization.

\section{Introduction}

Components of the innate immune system have recently come to the fore as significant contributors to vascular dysfunction and subsequent cardiovascular disease (Bomfim et al., 2017). However, the mediators of this pathophysiological response, as well as the exact mechanisms of their actions, are still being revealed (Bomfim et al., 2017). The Toll-like receptor (TLR) family is a class of innate immune system pattern recognition receptors that has been implicated in the pathogenesis of various cardiovascular conditions (McCarthy

This work was supported by the American Heart Association (Grants \#13PRE14080019, \#14POST20490292, and \#15GRNT25700451); the National Institutes of Health National Heart, Lung, and Blood Institute (Grant P01HL134604); and the National Institutes of Health National Institute of General Medical Sciences (Grant K99GM118885).

https://doi.org/10.1124/jpet.117.245746. et al., 2014; Goulopoulou et al., 2016). Of particular interest to our laboratory is TLR9, because of the elevated expression of its endogenous ligand mitochondrial DNA in different cardiovascular conditions (Veiko et al., 2010; Oka et al., 2012; McCarthy et al., 2015). We have recently reported that TLR9 is able to modulate vascular function and contribute to hypertension (McCarthy et al., 2015).

TLR9 has affinity for hypomethylated cytosine and guanine nucleotides separated by a phosphate-backbone (CpG). CpGs are common to prokaryotic DNA but not eukaryotic DNA, and this specificity is important for preventing TLR9-dependent autoimmune responses (Stacey et al., 2003). In naive cells, TLR9 is localized to the endoplasmic reticulum (ER) (Leifer et al., 2004), and upon cellular recognition of its ligand, it traffics through the Golgi to early endosomes and subsequently to endolysosomal compartments (Latz et al., 2004; Chockalingam et al., 2009).

ABBREVIATIONS: ACC, acetyl-CoA carboxylase; AMPK $\alpha, 5^{\prime}$-AMP-activated protein kinase $\alpha$; ANOVA, analysis of variance; AUC, area under the curve; CpG, cytosine-phosphate-guanine dinucleotide; eNOS, endothelial nitric oxide synthase; ER, endoplasmic reticulum; F, filamentous; G, globular; LKB1, liver kinase B1; MRA, mesenteric resistance artery; MyD88, myeloid differentiation primary response protein 88; MYPT1, myosin phosphatase target subunit 1; NE, norepinephrine; NF- $\kappa$ B, nuclear factor $\kappa$-light-chain-enhancer of activated B cells; ODN, oligonucleotide; PE, phenylephrine; \% $\mathrm{KCl}$, percentage of $\mathrm{KCl}$; PSS, physiological salt solution; ROCK, RhoA/Rho-associated protein kinase; SERCA2, sarcoplasmic/ endoplasmic reticulum $\mathrm{Ca}^{2+}$-ATPase 2; TAK1, transforming growth factor $\beta$-activated kinase 1; TLR, Toll-like receptor; VSMC, vascular smooth muscle cell. 
Traditionally in immune cells, TLR9 upregulates inflammatory mediators by signaling through a myeloid differentiation primary response gene 88 (MyD88)-dependent pathway after trafficking from the ER to endolysosomes (Klinman, 2004). However recently, a "noncanonical" pathway for TLR9 was reported in cardiomyocytes and neurons (Shintani et al., 2013, 2014). In this pathway, retrograde transport of unmethylated CpGs from endolysosomal compartments to the ER leads to the activation of uncleaved TLR9. TLR9 then directly inhibits the activity of sarcoplasmic reticulum/ER $\mathrm{Ca}^{2+}$-ATPase 2(SERCA2). As a result of impaired calcium uptake into the ER, mitochondrial calcium concentration decreases, leading to less mitochondrial ATP generation, and the resulting activation of 5'-AMP-activated protein kinase (AMPK $\alpha$ ).

Given that calcium handling is important for vascular smooth muscle contraction and relaxation, TLR9 inhibition of SERCA2 could be a mechanism for the increased contractile responses and the vascular dysfunction that we have previously reported (McCarthy et al., 2015). Therefore, we hypothesized that 1) this noncanonical stress tolerance pathway for TLR9 is present in vascular smooth muscle cells (VSMCs); and 2) in isolated arteries (denuded of endothelium), TLR9 activation inhibits SERCA2 and this contributes to enhanced contractile responses. To test these hypotheses, aortic microsomes, aortic VSMCs, and isolated mesenteric resistance arteries (MRAs) and aortae from male SpragueDawley rats were stimulated pharmacologically with a TLR9 agonist, ODN2395, and SERCA2 inhibition and AMPK $\alpha$ phosphorylation steps of the noncanonical stress tolerance signaling pathway were explored. Elucidation of this noncanonical pathway in vascular smooth muscle may be important in cardiovascular conditions that involve TLR9 activation (McCarthy et al., 2014; Goulopoulou et al., 2016).

\section{Materials and Methods}

\section{Animals}

Male Sprague Dawley rats (Envigo RMS, Indianapolis, IN), 12-20 weeks old, were used for all experiments, including isolated arteries, primary VSMC culture, and vascular microsomes. All rats were maintained on a 12-hour light/dark cycle with both chow and water available ad libitum. All procedures were performed in accordance with the Guide for the Care and Use of Laboratory Animals of the National Institutes of Health and were reviewed and approved by the Institutional Animal Care and Use Committee of Augusta University.

\section{Isolation of Arteries}

Rats were killed by thoracotomy and exsanguination via cardiac puncture under isoflurane anesthesia. MRAs and thoracic aortae were removed from rats and placed in a $4^{\circ} \mathrm{C}$ physiologic salt solution (PSS) containing the following: $\mathrm{NaCl}(130 \mathrm{mmol} / \mathrm{l}), \mathrm{NaHCO}_{3}(14.9 \mathrm{mmol} / \mathrm{l})$, $\mathrm{KCl}(4.7 \mathrm{mmol} / \mathrm{l}), \mathrm{KH}_{2} \mathrm{PO}_{4}(1.18 \mathrm{mmol} / \mathrm{l}), \mathrm{MgSO}_{4} \cdot 7 \mathrm{H}_{2} \mathrm{O}(1.18 \mathrm{mmol} / \mathrm{l})$, $\mathrm{CaCl}_{2} \cdot 2 \mathrm{H}_{2} \mathrm{O}(1.56 \mathrm{mmol} / \mathrm{l})$, EDTA $(0.026 \mathrm{mmol} / \mathrm{l})$, and glucose (5.5 mmol/l) (all Sigma-Aldrich, St Louis, MO). Excised arteries were cleaned of perivascular adipose tissue.

\section{Cell Culture}

Primary VSMCs were cultured from the thoracic aortae using an enzymatic digestion method (McGuire et al., 1993). Cells were then grown in a humidified chamber at $37^{\circ} \mathrm{C}$, with $5 \% \mathrm{CO}_{2}$, and low-glucose Dulbecco's Modified Eagle's Medium (GE Healthcare, Logan, UT) containing $10 \%$ fetal bovine serum (GE Healthcare) and 1\% penicillin/streptomycin solution (Corning, Manassas, VA). Treatments commenced between passages 3 and 6 , when culture dishes were $\geq 80 \%$ confluent. Twenty-four hours prior to treatments, cells were placed into serum-free media to achieve quiescence.

\section{Isolation of Vascular Microsomes}

Microsomes were extracted from pooled aortae (eight per sample) via homogenization and differential ultracentrifugation, as previously described (Webb and Bhalla, 1976). Samples were resuspended in $50 \mu \mathrm{l}$ of a specialized SERCA2 reaction solution containing the following: Tris- $\mathrm{HCl}(20 \mathrm{mmol} / \mathrm{l}), \mathrm{KCl}(100 \mathrm{mmol} / \mathrm{l}), \mathrm{MgCl}_{2}(2 \mathrm{mmol} / \mathrm{l})$, ATP $(2 \mathrm{mmol} / \mathrm{l}), \mathrm{CaCl}_{2}(0.5 \mu \mathrm{mol} / \mathrm{l})$, and oxalate $(7.5 \mathrm{mmol} / \mathrm{l})$ (all Sigma-Aldrich), $\mathrm{pH} 7.4$.

\section{Treatment}

Isolated arteries in PSS, VSMCs in serum-free media, and microsomes in SERCA2 reaction solution were incubated for 20 minutes with either vehicle (endotoxin-free water; InvivoGen, San Diego, CA) or a TLR9 agonist, type C synthetic CpG oligonucleotide (ODN) ODN2395 (2 $\mu \mathrm{mol} / \mathrm{l}$; InvivoGen). In some experiments, the classic SERCA2 inhibitor thapsigargin $(1 \mu \mathrm{mol} / \mathrm{l}$; Tocris Bioscience, Ellisville, MO) was used as a positive control. To elucidate the signaling by which ODN2395 exerts its effects, different inhibitors were applied 30 minutes before vehicle or ODN2395. These inhibitors included the TLR9 antagonist suppressive ODN ODN2088 (20 $\mu \mathrm{mol} / \mathrm{l}$; InvivoGen); AMPK $\alpha$ inhibitor compound C (10 $\mu \mathrm{mol} / \mathrm{l}$; EMD Millipore, Billerica, MA); thapsigargin ( $1 \mu \mathrm{mol} / \mathrm{l})$; transforming growth factor $\beta$-activated kinase 1 (TAK1) inhibitor (57)-7-oxozeaenol (100 nmol/l; Tocris Bioscience); vacuolar $\mathrm{H}^{+}$-ATPase inhibitor bafilomycin A1 (10 nmol/l; Tocris Bioscience); and RhoA/RhoA/Rho-associated protein kinase (ROCK) inhibitor Y-27632 dihydrochloride (1 $\mu \mathrm{mol} / \mathrm{l}$; Sigma-Aldrich).

\section{Western Blotting}

Isolated Arteries. After treatment, arteries were flash frozen in liquid nitrogen and homogenized in ice-cold tissue protein extraction reagent (T-PER; Thermo Fisher Scientific, Waltham, MA), with protease inhibitors (sodium orthovanadate, phenylmethylsulfonyl fluoride, protease inhibitor cocktail) and phosphatase inhibitors (sodium fluoride and sodium pyrophosphate) (all Sigma-Aldrich).

Cell Cultures. After treatment, cells were washed with an ice-cold phosphate-buffered saline (PBS) solution. Complete Lysis-M, including a phosphatase inhibitor cocktail (PhosSTOP) (both Roche, Indianapolis, IN), was then applied to each plate and allowed to remain on ice for 30 minutes. Cells were then harvested.

The protein concentration of both cell and tissue lysates was first determined and then equal quantities of protein (between 20 and $40 \mu \mathrm{g})$ were loaded into polyacrylamide gels $(8 \%-12 \%)$ and separated by SDS-PAGE. Gels were then transferred to polyvinylidene difluoride membranes (Thermo Fisher Scientific) and probed for protein expression (Table 1). Phosphorylated proteins were normalized to their total form, and $\beta$-actin was used as the loading control. Densitometric analysis was performed by Un-Scan-It (version 6.1) (Silk Scientific, Orem, UT).

\section{Vascular Function}

MRAs were mounted on DMT wire myographs (Danish MyoTech, Aarhus, Denmark), and the endothelium was denuded by rubbing the lumen with a hair shaft. Arteries were then bathed in $37^{\circ} \mathrm{C}$ PSS with $5 \% \mathrm{CO}_{2}$ and $95 \% \mathrm{O}_{2}$ and normalized to their optimal lumen diameter for active tension development, as described previously (McCarthy et al., 2015). Arteries were initially contracted to $\mathrm{KCl}(120 \mathrm{mmol} / \mathrm{l})$, and endothelium integrity was then tested by the application of phenylephrine (PE; Sigma-Aldrich) $(3 \mu \mathrm{mol} / \mathrm{l})$ followed by acetylcholine (Sigma-Aldrich) $(3 \mu \mathrm{mol} / \mathrm{l})$. Arteries were considered viable if $\mathrm{KCl}$ and $\mathrm{PE}$ contracted the arteries greater than $10 \mathrm{mN}$, respectively, and 
TABLE 1

Proteins probed for in Western blots

This table contains a list of the specific antibodies used in the current article, including dilutions, secondary antibody host species, and the company from which the antibody was purchased.

\begin{tabular}{|c|c|c|c|}
\hline Protein & Dilution & Secondary Antibody & Company/Catalog \# \\
\hline Phosphorylated AMPK $\alpha^{\text {Thr172 }}$ & $1: 1000$ & Rabbit & Cell Signaling Technology/2535 \\
\hline Total AMPK $\alpha$ & $1: 1000$ & Rabbit & Cell Signaling Technology/2532 \\
\hline Phosphorylated ACC ${ }^{\text {Ser79 }}$ & $1: 1000$ & Rabbit & Cell Signaling Technology/3661 \\
\hline Total ACC & $1: 1000$ & Rabbit & Cell Signaling Technology/3676 \\
\hline Phosphorylated TAK1 $1^{\text {Thr184/187 }}$ & $1: 1000$ & Rabbit & Thermo Fisher Scientific/MA5-15073 \\
\hline Total TAK1 & $1: 1000$ & Rabbit & Cell Signaling Technology/4505 \\
\hline Phosphorylated MYPT $1^{\text {Thr696 }}$ & $1: 1000$ & Rabbit & Cell Signaling Technology/5163 \\
\hline Total MYPT1 & $1: 1000$ & Mouse & $\begin{array}{l}\text { BD Transduction Laboratories } \\
\text { (San Jose, CA)/612165 }\end{array}$ \\
\hline Phosphorylated cofilin ${ }^{\text {Ser3 }}$ & $1: 1000$ & Rabbit & Cell Signaling Technology/3311 \\
\hline Total cofilin & $1: 1000$ & Rabbit & Cell Signaling Technology/3318 \\
\hline Phosphorylated LKB1 ${ }^{\text {Ser428 }}$ & $1: 1000$ & Rabbit & Cell Signaling Technology/3482 \\
\hline Total LKB1 & $1: 1000$ & Rabbit & Cell Signaling Technology/3047 \\
\hline$\beta$-actin & $1: 50,000$ & Mouse & Sigma-Aldrich/A3854 \\
\hline
\end{tabular}

endothelium denudation was considered successful if arteries relaxed less than $25 \%$ to acetylcholine. Arteries then rested for 10 minutes, after which they were subjected to one of the following three protocols.

In PSS, MRAs were first stimulated with PE (3 $\mu \mathrm{mol} / \mathrm{l})$. Upon plateau of the contractile response, the MRAs were washed in calciumfree PSS + EGTA (Sigma-Aldrich) for 20 minutes to deplete intracellular calcium stores . During the depletion period, the MRAs were also incubated with vehicle, ODN2395, or thapsigargin. After calcium depletion, intracellular calcium stores were loaded by placing the MRAs in normal PSS ( $1.6 \mathrm{mmol} / \mathrm{l}$ calcium) for 15 minutes. Contractile responses during the loading period were taken as a functional measure of calcium influx (calcium loading). The bathing medium was then replaced again with calcium-free PSS (no EGTA). After 5 minutes, the MRAs were stimulated with caffeine (SigmaAldrich) (20 mmol/l) to deplete intracellular calcium stores, which resulted in a transient contraction. The magnitude of this last response was taken as a measure of the ER to release calcium (intracellular calcium release). This protocol has been successfully employed in our laboratory (Giachini et al., 2009). Results are presented as a percentage of the $\mathrm{KCl}$ contraction $(\% \mathrm{KCl})$.

In PSS, MRAs were first incubated with vehicle, ODN2395, or thapsigargin for 20 minutes. Then MRAs were contracted with norepinephrine (NE; $3 \mu \mathrm{mol} / \mathrm{l}$ ) (Sigma-Aldrich), and upon plateau the PSS was washed one time and replaced. The time for contracted arteries to achieve maximum relaxation was measured. This protocol has been successfully employed in our laboratory (Tostes et al., 1995). Results are presented in units of time (seconds).

In PSS, MRAs were first incubated with or without compound C for 30 minutes. Then MRAs were incubated with vehicle or ODN2395 for a further 20 minutes. Finally, MRAs were contracted with PE (10 $\mu \mathrm{mol} / \mathrm{l}$ ), and upon plateau cumulative concentration-response curves were performed to Y-27632 $(1 \mathrm{nmol} / \mathrm{l}$ to $30 \mu \mathrm{mol} / \mathrm{l})$. Results are presented as the percentage relaxation to the PE-induced contraction.

\section{Luciferase Assay}

The activity of SERCA2 was also assessed using a luciferase assay in which ATP was quantified using an ATP Determination Kit (Invitrogen, Grand Island, NY). This assay utilizes requirement of luciferase for ATP in producing light.

Protein concentration of isolated microsomes was determined, and $35 \mu \mathrm{g}$ of protein was incubated in a combined SERCA2 and luciferase reaction solution. The SERCA2 reaction solution was as described above, and the luciferase reaction solution was made according to manufacturer instructions, with the exception of using the SERCA2 reaction solution instead of deionized water. Microsomes were then subjected to treatment with vehicle or ODN2395, with and without thapsigargin. Luminescence was then read with a luminometer
(BioTek, Winooski, VT) at 5, 10, 20, 40, and 60 minutes, and an ATP decay curve was constructed.

\section{Coimmunoprecipitation}

Endothelium-intact MRAs were isolated, cleaned of perivascular adipose tissue, and pooled (two per sample). Homogenization was performed as described above for Western blotting. After protein concentration determination, $260 \mu \mathrm{g}$ of protein was immunoprecipitated with either mouse anti-TLR9 (1:50; catalog \#ab12121; Abcam, Cambridge, MA) or rabbit anti-SERCA2 (1:50; catalog \#4388; Cell Signaling Technology, Danvers, MA) for 2 hours at $4^{\circ} \mathrm{C}$, followed by incubation with Protein A/G PLUS-Agarose (Santa Cruz Biotechnology, Dallas, TX) for another 24 hours at $4^{\circ} \mathrm{C}$. Samples were then washed four times with ice-cold T-PER with protease inhibitors and centrifuged at $1500 \mathrm{~g}$ for 5 minutes at $4^{\circ} \mathrm{C}$ after each wash. After the fourth wash, the supernatant was discarded and $50 \mu \mathrm{l}$ of $2 \times$ SDS sample buffer was added. Samples were then heated at $100^{\circ} \mathrm{C}$ for 10 minutes before being loaded into SDS-PAGE gels (7.5\%) and transferred onto nitrocellulose membranes (Bio-Rad, Hercules, CA). Finally, membranes were immunoblotted for the expression of SERCA2 (if TLR9 was immunoprecipitated) or TLR9 (if SERCA2 was immunoprecipitated) (both 1:1000 dilution).

\section{Filamentous and Globular Actin Quantification}

VSMCs were processed according to a globular (G) actin/filamentous (F) actin In Vivo Assay Kit (Cytoskeleton, Inc., Denver, CO). Briefly, VSMCs were lysed in a detergent-based buffer that stabilizes the $\mathrm{G}$ and $\mathrm{F}$ forms of actin. Ultracentrifugation was then used to separate them, pelleting the $\mathrm{F}$ actin and leaving the $\mathrm{G}$ actin in the supernatant. After collecting the $\mathrm{G}$ actin, the $\mathrm{F}$ actin was depolymerized. Finally, the $\mathrm{F}$ and $\mathrm{G}$ actin samples were loaded into polyacrylamide gels (10\%), separated by SDS-PAGE, and transferred to polyvinylidene difluoride membranes, as described above for Western blotting. Known quantities of actin control protein were included as standards. Densitometric analysis was performed by Un-Scan-It (version 6.1) (Silk Scientific).

\section{Confocal Microscopy}

To visualize $\mathrm{F}$ actin bundles and focal adhesion protein paxillin, VSMCs were grown in Laboratory-Tek II Chamber Slide w/Covers (Thermo Fisher Scientific), and confocal microscopy was performed. After treatment, VSMCs were fixed in $4 \%$ paraformaldehyde (Thermo Fisher Scientific) for 10 minutes and blocked in $1 \times$ PBS with $0.01 \%$ Triton X-100 (Thermo Fisher Scientific) and 5\% horse serum. The slides were then incubated with rabbit anti-paxillin (1:100; catalog \#ab32084; Abcam) primary antibody in $1 \times$ PBS and $5 \%$ bovine serum albumin overnight. Next, slides were incubated with goat anti-rabbit 
IgG (H + L) Cross-Adsorbed Secondary Antibody Alexa Fluor 488 (1: 200; catalog \#A-11008; Thermo Fisher Scientific) and rhodamine phalloidin (1:40; catalog \#R415; Thermo Fisher Scientific/) in 1× PBS and $5 \%$ bovine serum albumin for 90 minutes. Vectashield HardSet Antifade Mounting Medium with DAPI (4',6-diamidino-2phenylindole, dihydrochloride; catalog \#H-1500; Vector Laboratories, Inc., Burlingame, CA) was then applied to slides with coverslips. VSMCs were visualized using a Zeiss LSM 780 Upright Confocal Microscope ( $63 \times$ objective) (Carl Zeiss MicroImaging, Oberkochen, Germany).

\section{Statistical Analysis}

The sample size indicated per experiment (see figure legends) is the number of independent rats (or pooled samples) used, respective of treatment group. The statistical procedures used included one-way and two-way analyses of variance (ANOVAs) and Student's $t$ tests. Tukey's post hoc testing was performed in the event of a significant one-way ANOVA, and a Bonferroni correction was used in the event of a significant two-way ANOVA. All analyses were performed using data analysis software GraphPad Prism 5.0 (GraphPad, La Jolla, CA). Statistical significance was set at $P<0.05$. The data are presented as the mean \pm S.E.M.

\section{Results}

TLR9 Activation Increases Vascular PhosphoAMPK $\boldsymbol{\alpha}^{\text {Thr172 }}$ Expression. To test our first hypothesis that the noncanonical stress tolerance signaling cascade is present in VSMCs, we probed for the expression of activated AMPK $\alpha$, which is the ultimate step of the pathway (Shintani et al., 2013, 2014). After pharmacologically activating TLR9 with ODN2395 ( $2 \mu \mathrm{mol} / \mathrm{l})$, we observed that phospho-AMPK $\alpha^{\text {Thr172 }}$ was significantly increased in isolated arteries (MRA, aorta, and endothelium denuded aorta), as well as VSMCs (Fig. 1, A-D). Importantly, the pretreatment of isolated arteries and VSMCs with TLR9 antagonist (ODN2088; $20 \mu \mathrm{mol} / \mathrm{l}$ ) blocked this response, indicating that this increase in phospho$\operatorname{AMPK} \alpha^{\text {Thr172 }}$ was specific to TLR9. Further supporting that ODN2395 activates AMPK $\alpha$, we probed for the expression of phosphorylated acetyl-CoA carboxylase (ACC), which is one of the major enzymes regulated by AMPK $\alpha$. We observed that ODN2395 significantly increased phospho-ACC ${ }^{\text {Ser79 }}$ in VSMCs, and this increase was prevented by pretreatment of the cells with an AMPK $\alpha$ inhibitor, compound C (10 $\mu \mathrm{mol} / \mathrm{l})$ (Fig. 1E). Overall, these data suggest the presence of the noncanonical stress tolerance signaling cascade in VSMCs.

TLR9 Activation Does Not Impair SERCA2 Activity, nor Does It Promote TLR9-SERCA2 Colocalization. To further test for the presence of the noncanonical stress tolerance signaling cascade in VSMCs, we performed a series of SERCA2 activity assays, because the inhibition of SERCA2 is an important early step in the pathway (Shintani et al., 2013, 2014). Denuded MRAs were mounted on wire myographs to evaluate force development in response to calcium influx after the depletion of intracellular calcium stores (calcium loading) and after caffeine $(20 \mathrm{mmol} / \mathrm{l})$ stimulation to measure the functional capacity of the ER to release calcium (intracellular calcium release). During the calcium loading periods, force development was not different between vehicle and ODN2395, but it was increased by thapsigargin (positive control; $1 \mu \mathrm{mol} / \mathrm{l})(\% \mathrm{KCl}$ : vehicle, $3.26 \pm 1.27$; ODN2395, 2.80 \pm 1.28 ; thapsigargin, $10.23 \pm 2.51 ; * P<0.05)($ Fig. $2 \mathrm{~A}$ ). The magnitude of the contractile responses to caffeine was also not different between vehicle and ODN2395, but the responses were decreased by thapsigargin $(\% \mathrm{KCl}$ : vehicle, $23.69 \pm 4.67$; ODN2395, $20.84 \pm 3.18$; thapsigargin, $2.04 \pm 0.53 ; * P<0.05$ ) (Fig. 2B). Similarly, the time for denuded MRA to reach maximum relaxation after contraction to $\mathrm{NE}$ was not different between vehicle and ODN2395, but it was increased by thapsigargin (Fig. 2C). Overall, these vascular function data suggest that SERCA2 activity is not impaired when isolated MRAs, denuded of endothelium, are treated with TLR9 agonist ODN2395.

To understand the contribution of TLR9 to SERCA2 activity at the molecular level, microsomes were isolated from pooled aortae. Microsomes are fragments of the ER that we have previously extracted for analyzing SERCA2 activity and intracellular calcium sequestration (Webb and Bhalla, 1976). As SERCA2 is an ATPase, we used a luciferase assay to measure ATP concentration, and thapsigargin was applied as a pharmacological tool to obtain SERCA2 specificity. The presence of thapsigargin in both vehicle- and ODN2395treated microsomes significantly increased the concentration of ATP at all time points (with the exception of 20 minutes in ODN2395, which was trending; $P=0.08$ ) (Fig. 2D). Area under the curve (AUC) analysis of ATP decay across the 60 minutes of measurement revealed that ATP concentration in the vehicle-incubated microsomes was low, which is indicative of ATP consumption with functional SERCA2 activity, and this significantly increased when vehicle incubated microsomes were pretreated with thapsigargin [ATP concentration (AUC): vehicle, $19 \pm 3$; vehicle + thapsigargin, $140 \pm$ $35 ; * P<0.05]$. Similarly, ATP concentration in ODN2395incubated microsomes was low, and this significantly increased when ODN2395-incubated microsomes were pretreated with thapsigargin [ATP concentration (AUC): ODN2395, $22 \pm 9$; ODN2395 + thapsigargin, $129 \pm 12$; $* P<0.05$ ]. Importantly, no significant difference in ATP concentration was observed between vehicle- and ODN2395treated microsomes (Fig. 2E). To support these data, coimmunoprecipitation was performed for TLR9 with SERCA2, and vice versa, in MRAs incubated with vehicle or ODN2395. Unlike in the study by Shintani et al. (2014), in cardiomyocytes there was no observable protein-protein interaction between TLR9 and SERCA2 in MRAs stimulated with ODN2395 (Fig. 2F). Finally, to support the mechanism that SERCA2 inhibition can induce AMPK $\alpha$ phosphorylation, we investigated whether the classic SERCA2 inhibitor thapsigargin could increase phospho-AMPK $\alpha^{\text {Thr172 }}$. In isolated MRAs, thapsigargin did not increase the expression of phosphoAMPK $\alpha^{\text {Thr172 }}$ (Fig. 2G). These experiments further reinforce that TLR9 activation with ODN2395 does not inhibit vascular smooth muscle SERCA2 activity, and an increase in cytosolic calcium concentration due to SERCA2 inhibition is insufficient to induce AMPK $\alpha$ phosphorylation in isolated arteries.

Inhibition of TAK1 Prevents TLR9-Dependent AMPK $\boldsymbol{\alpha}^{\text {Thr172 }}$ Phosphorylation. Given that SERCA2 activity was not impaired by TLR9 activation with ODN2395, and that SERCA2 inhibition with thapsigargin did not increase phospho-AMPK $\alpha^{\text {Thr172 }}$, an alternative mechanism of AMPK $\alpha$ activation was pursued. Upon investigation of upstream kinases and activators of AMPK $\alpha$, as well as canonical TLR9-inflammatory signaling, TAK1 was identified as a potential mediator of AMPK $\alpha$ phosphorylation (Momcilovic et al., 2006; Xie et al., 2006). Accordingly, we observed that 
A

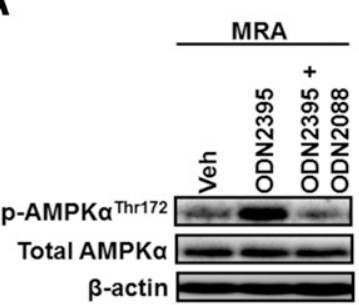

B

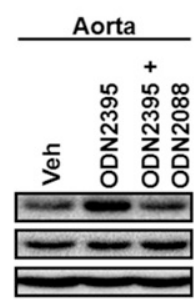

C

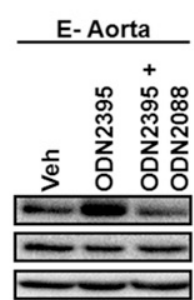

D
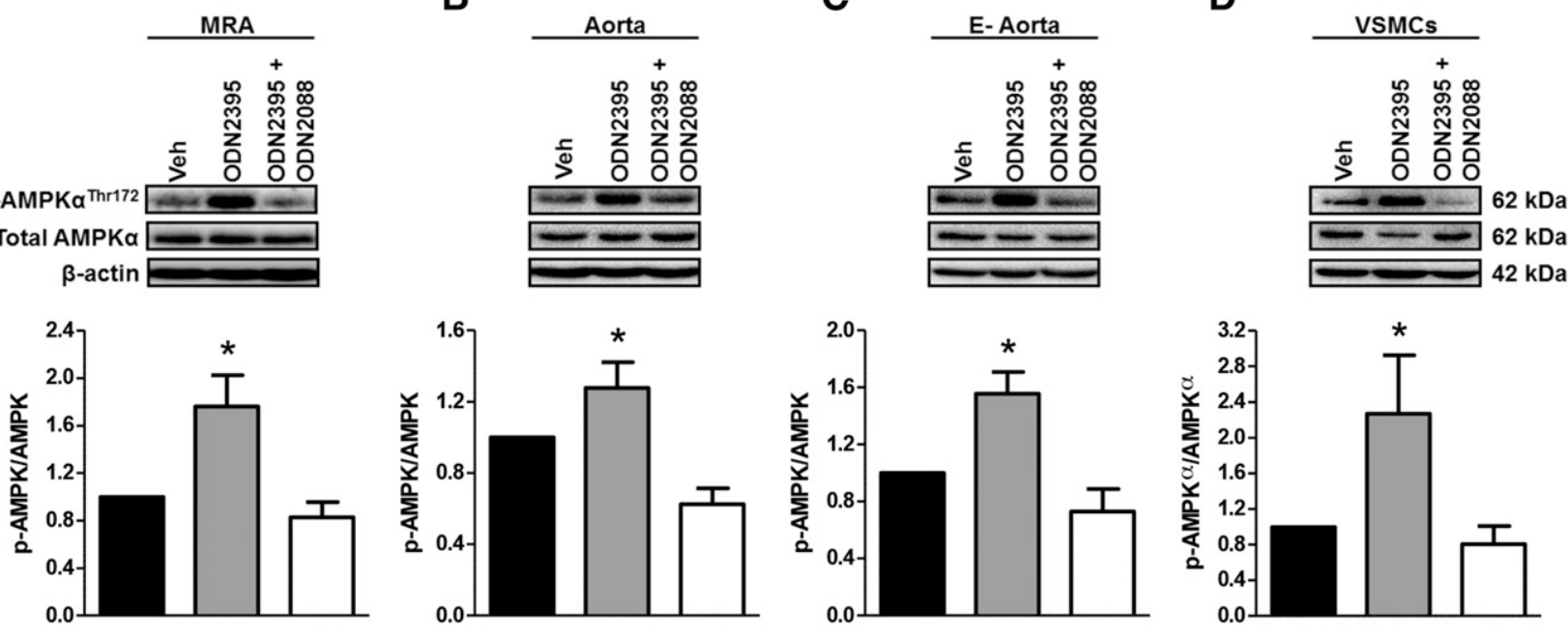

这
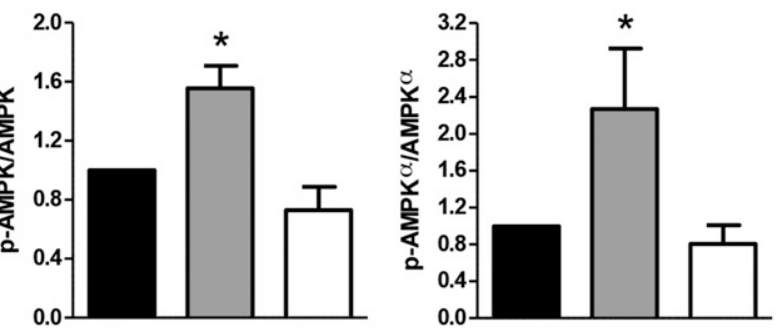

Veh

ODN2395

ODN2395+ODN2088

E

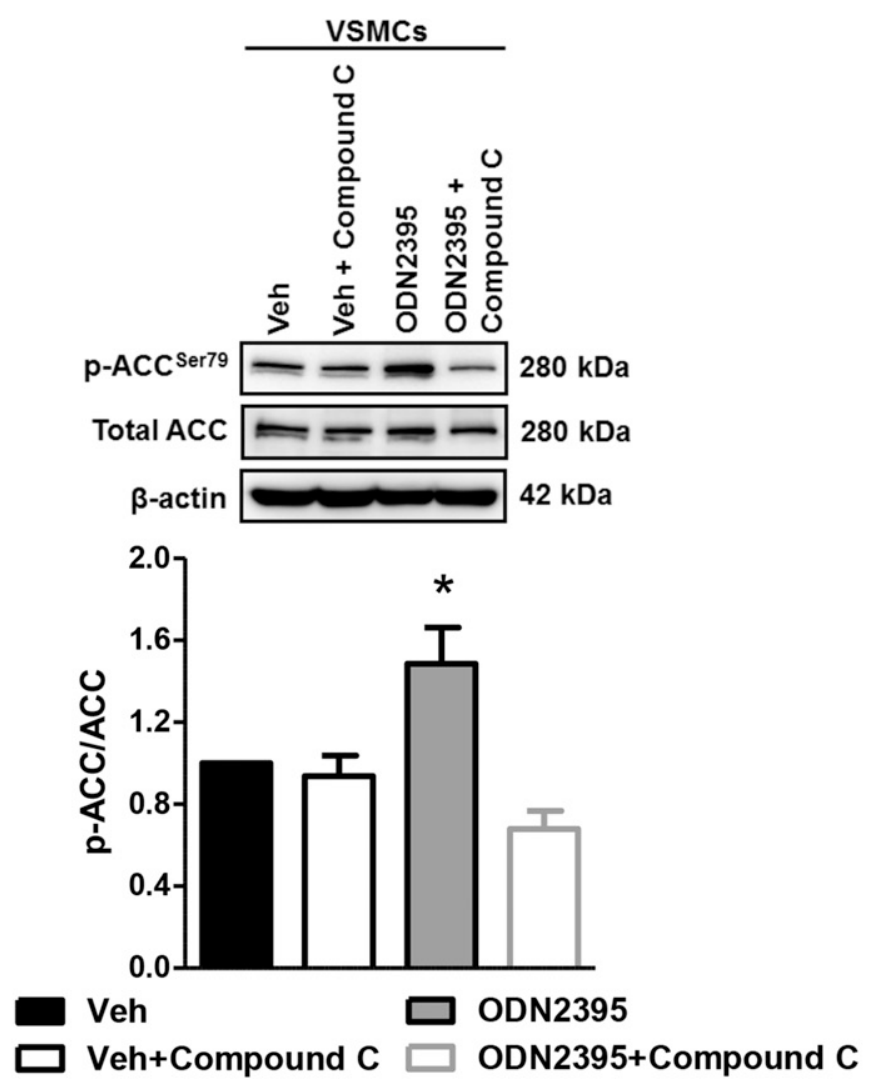

Fig. 1. TLR9 agonist ODN2395 increases phospho-AMPK $\alpha^{\text {Thr172 }}$ expression in isolated arteries and VSMCs. Protein expression analysis was performed for phospho (p)-AMPK $\alpha^{\text {Thr172 }}$ normalized to total AMPK $\alpha$ in MRAs (A), aorta (B), endothelium denuded (E-) aorta (C), and VSMCs (D) incubated in either vehicle (Veh) or ODN2395 (2 $\mu \mathrm{mol} / \mathrm{l})$, with and without ODN2088 (20 $\mu \mathrm{mol} / \mathrm{l})$. (E) Protein expression analysis for phospho-ACC ${ }^{\text {Ser79 }}$ normalized to total ACC was performed in VSMCs incubated in either vehicle or ODN2395, with and without compound C (10 $\mu$ mol/l). Above, representative images of immunoblots; below, densitometric analysis. $n=4-8$. One-way ANOVA: $* P<0.05$ vs. vehicle.

pretreatment of VSMCs with TAK1 inhibitor (57)-7-oxozeaenol (100 nmol/l) prevented the ODN2395-dependent increase in phospho-AMPK $\alpha^{\text {Thr172 }}$ (Fig. 3A). Supporting these data, the activated form of TAK1, phospho-TAK1 ${ }^{\text {Thr184/187, was signif- }}$ icantly increased after ODN2395 treatment compared with vehicle, and pretreatment with ODN2088 blocked this response (Fig. 3B). To corroborate that AMPK phosphorylation was coming from endolysosomal compartments, we pretreated some VSMCs with vacuolar $\mathrm{H}^{+}$-ATPase inhibitor bafilomycin A1 (10 nmol/l), which prevents endolysosome acidification and, therefore, TLR9 signaling specifically from the inflammatory canonical pathway. We observed that 
A

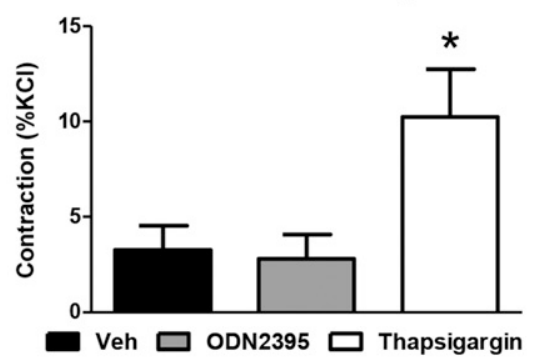

C

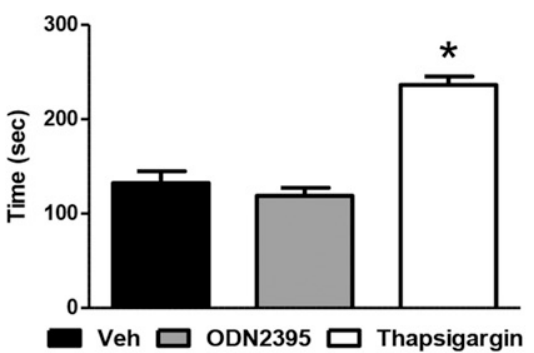

B Intracellular calcium release

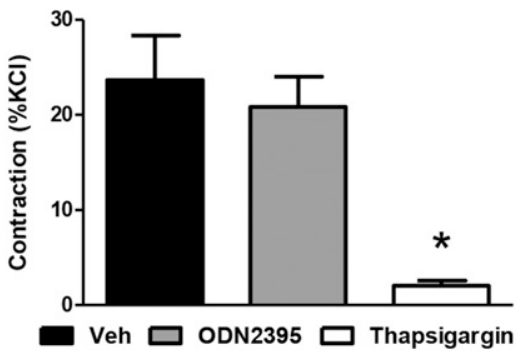

D

E
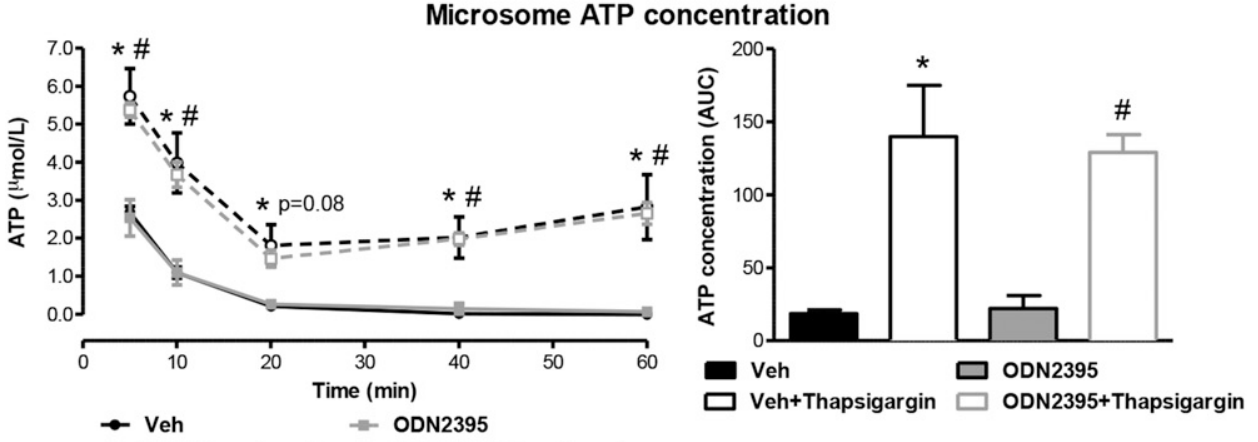

- - Veh+Thapsigargin - - ODN2395+Thapsigargin

$\mathbf{F}$

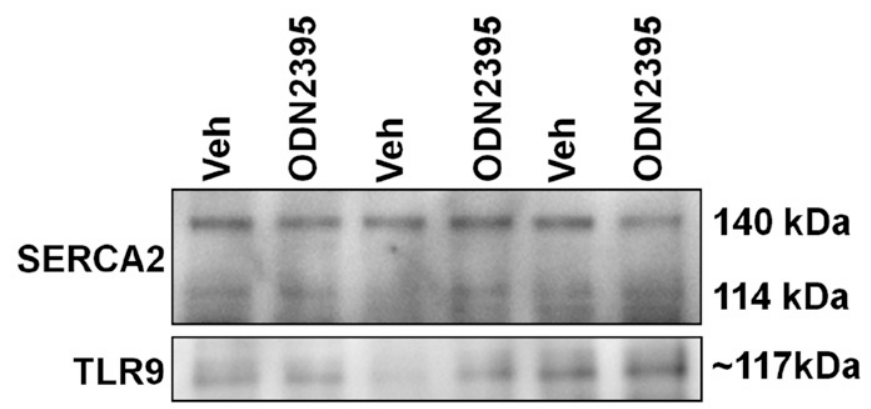

G

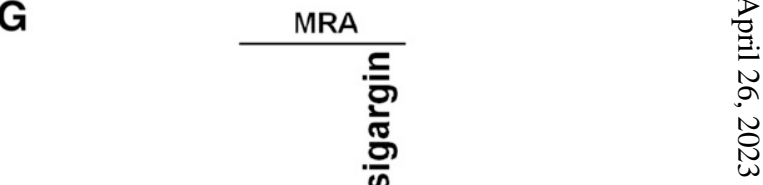

Fig. 2. TLR9 agonist ODN2395 does not impair SERCA2 activity, unlike classic SERCA2 inhibitor thapsigargin, or promote TLR9-SERCA2 colocalization in vascular tissues. In denuded MRAs incubated in vehicle (Veh), ODN2395 ( $2 \mu \mathrm{mol} / \mathrm{l})$, or thapsigargin ( $1 \mu \mathrm{mol} / \mathrm{l})$, contractile responses were measured during calcium loading (A), after intracellular calcium release (B), and in the time to achieve maximum relaxation after NE washout (C). ATP concentration was measured in isolated microsomes $(n=5 ; 8$ pooled aortae/sample), incubated in either vehicle or ODN2395, with or without 
bafilomycin A1 also prevented the ODN2395-dependent increase in phospho-AMPK $\alpha^{\text {Thr172 }}$ (Fig. 3C), supporting the data with TAK1 inhibitor (57)-7-oxozeaenol. Interestingly, the phosphorylation of AMPK $\alpha$ in VSMCs appears to be a direct effect of TAK1, and not an indirect effect via liver kinase B1 (LKB1) (Fig. 3D). Overall, these data suggest that AMPK $\alpha$ is phosphorylated as a result of TLR9 inflammatory signaling (via TAK1) in VSMCs.

TLR9 Increases Actin Polymerization and This Is Associated With AMPK $\alpha$-RhoA/ROCK Signaling. AMPK $\alpha$ is a multifunctional cell survival kinase, capable of regulating a number of cellular processes (Viollet et al., 2010), especially in the vasculature (Salt and Hardie, 2017). Given the vascular dysfunction we previously observed in rats treated with ODN2395 (McCarthy et al., 2015), we hypothesized that TLR9-AMPK $\alpha$ signaling may be inducing dysfunction via reorganization of the actin cytoskeleton (Zheng and Cantley, 2007; Miranda et al., 2010). Accordingly, we observed that ODN2395 treatment increases the $\mathrm{F}$ actin-to-G actin ratio in VSMCs (Fig. 4A). To support these quantitative data, we performed confocal microscopy on VSMCs after incubation with vehicle and ODN2395. Despite no obvious differences in the immunofluorescence of focal adhesion protein paxillin, the intensity of rhodamine-phalloidin staining, indicative of $\mathrm{F}$ actin, was clearly increased in VSMCs treated with ODN2395, and these $\mathrm{F}$ actin bundles also exhibited an element of disorganization compared with vehicle-treated VSMCs (Fig. 4B).

Given that the Rho signaling governs the global organization of $\mathrm{F}$ actin (Hall, 1998), we further hypothesized that ODN2395 increases ROCK activation via AMPK $\alpha$ to regulate actin polymerization. We observed that AMPK $\alpha$ inhibition with compound $\mathrm{C}$ increased the relaxation of vehicle-treated denuded MRAs to RhoA/ROCK inhibitor Y-27632 (Fig. 5A), indicating that RhoA/ROCK is activated by AMPK $\alpha$ in the basal condition of our vascular reactivity preparation. Similarly, compound $\mathrm{C}$ also potentiated the relaxation to Y-27632 in ODN2395-treated denuded MRAs (Fig. 5B), but this increase in relaxation occurred to a much greater extent (Fig. 5C), indicating that RhoA/ROCK activation by AMPK $\alpha$ is increased after ODN2395 treatment. Supporting these vascular function data, Western blotting was performed for RhoA/ROCK substrate myosin phosphatase target subunit 1 (MYPT1), with the phosphorylated form of this protein being an indicator of active RhoA/ROCK signaling. We observed that ODN2395 significantly increased phospho-MYPT1 $1^{\mathrm{Th} 696}$ in VSMCs, and this increase was prevented by pretreatment of the cells with compound C (Fig. 5D).

Cofilin is an actin-severing protein that can depolymerize actin filaments. Therefore, its inactivation via phosphorylation, which can be modulated by ROCK (Maekawa et al., 1999), stabilizes $\mathrm{F}$ actin and promotes its accumulation (Moon and Drubin, 1995). Therefore, we hypothesized that TLR9 activation with ODN2395 would increase cofilin phosphorylation, thereby abrogating its activity.
We observed that ODN2395 significantly increased phospho-cofilin ${ }^{\mathrm{Ser} 3}$ in VSMCs, and this increase was prevented by pretreatment of the cells with Y-27632 $(1 \mu \mathrm{mol} / \mathrm{l})$ (Fig. $5 \mathrm{E})$. Interestingly, Y-27632 also lowered the phosphocofilin $^{\text {Ser3 }}$ expression in our vehicle-treated VSMCs, again suggesting that that RhoA/ROCK is activated to a small degree in the basal condition of our cell culture preparation (Fig. 5E).

\section{Discussion}

The present investigation reveals three significant discoveries surrounding TLR9 signaling in VSMCs. The first major finding was that AMPK $\alpha$ activation downstream of TLR9 appears to be an extension of canonical inflammatory signaling via TAK1. Second, the noncanonical stress tolerance signaling cascade for TLR9, which is initiated by SERCA2 inhibition and has been reported in cardiomyocytes and neurons, is not present in VSMCs. Finally, TLR9AMPK $\alpha$ signaling can activate RhoA/ROCK and promote the accumulation of $\mathrm{F}$ actin (Fig. 6). These data support a novel mechanism by which TLR9 can impact vascular function and potentially contribute to the pathogenesis of cardiovascular diseases (McCarthy et al., 2014; Goulopoulou et al., 2016).

Previously, we have reported that arteries from rats treated in vivo with TLR9 agonist ODN2395 present significant dysfunction (McCarthy et al., 2015). These data add to the growing body of literature illustrating that the activation of almost all TLRs (including those located on endosomes and the plasma membrane) can impact vascular function through various mechanisms (McCarthy et al., 2014; Goulopoulou et al., 2016). Given the well-established role of TLRs, including TLR9, in vascular (patho)physiology, in the present study we wanted to understand further the mechanisms underlying TLR9-dependent vascular dysfunction, and specifically whether TLR9 activation inhibits vascular smooth muscle SERCA2 and contributes to enhanced contractile responses.

To fully understand the significance and novelty of the TLR9 noncanonical signaling cascade reported by Shintani et al. $(2013,2014)$, one must understand the multistep, tightly regulated processing prior to canonical TLR9 (inflammatory) activation (Goulopoulou et al., 2016). In contrast, the TLR9 noncanonical signaling pathway was reported to cause SERCA2 inhibition and ultimately resulted in AMPK $\alpha$ activation. In the current investigation, regardless of our experimental approach (isolated arteries ex vivo and aortic microsomes in vitro), we were not able to observe any evidence of SERCA2 inhibition after treatment with TLR9 agonist ODN2395. Despite the lack of effect on SERCA2 activity, we observed clear AMPK $\alpha$ phosphorylation at its activation site, threonine 172, suggesting that AMPK $\alpha$ activation downstream of TLR9 was occurring through some other mechanism. Supporting an alternative mechanism was the observation that SERCA2 inhibition with thapsigargin was also not sufficient to induce $\operatorname{AMPK} \alpha$ phosphorylation in

thapsigargin, across a 60-minute time course (D) and summated as the AUC (E). (F) Coimmunoprecipitation was performed for TLR9 with SERCA2 in MRAs incubated with vehicle or ODN2395 ( $n=3 ; 2$ pooled MRAs/sample). (G) Protein expression analysis was performed for phospho (p)-AMPK $\alpha^{\text {Thr172 }}$ normalized to total AMPK $\alpha$ in MRAs incubated with vehicle or thapsigargin. Above, representative images of immunoblots; below, densitometric analysis. $n=3-6$. One-way ANOVA, ${ }^{*} P<0.05$ vs. vehicle; two-way ANOVA, $* P<0.05$ vs. vehicle, $\# P<0.05$ vs. ODN2395. 
A

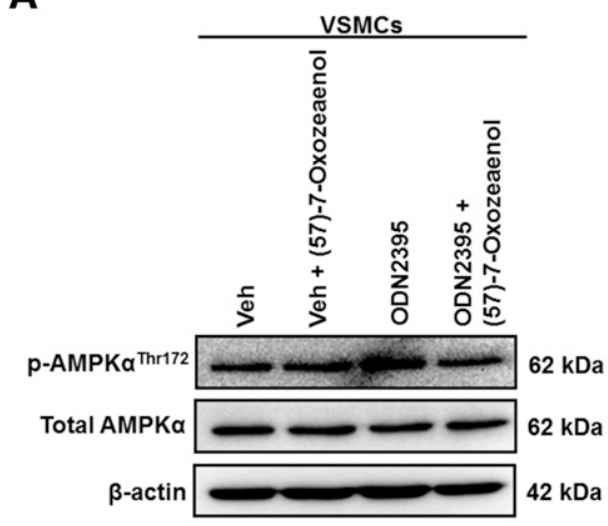

B
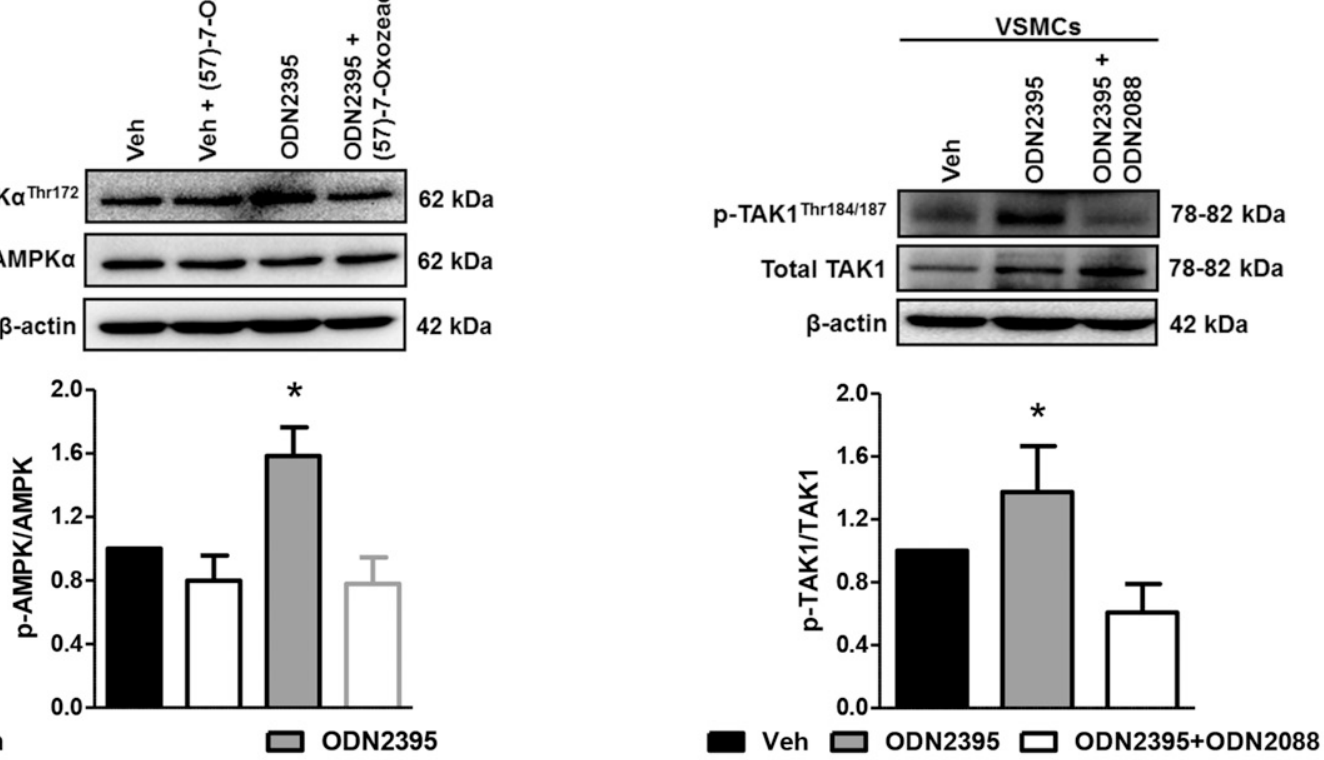

Veh

ODN2395

Veh

Veh+(57)-7-Oxozeaenol

ODN2395+(57)-7-Oxozeaenol

C
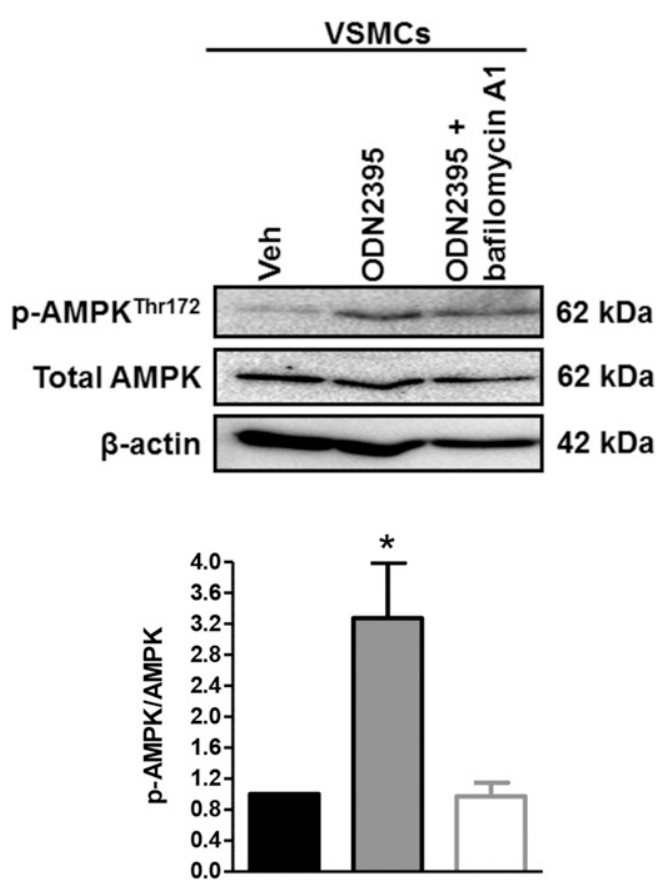

Veh $\square$ ODN2395 $\square$ ODN2395+bafilomycin A1
D
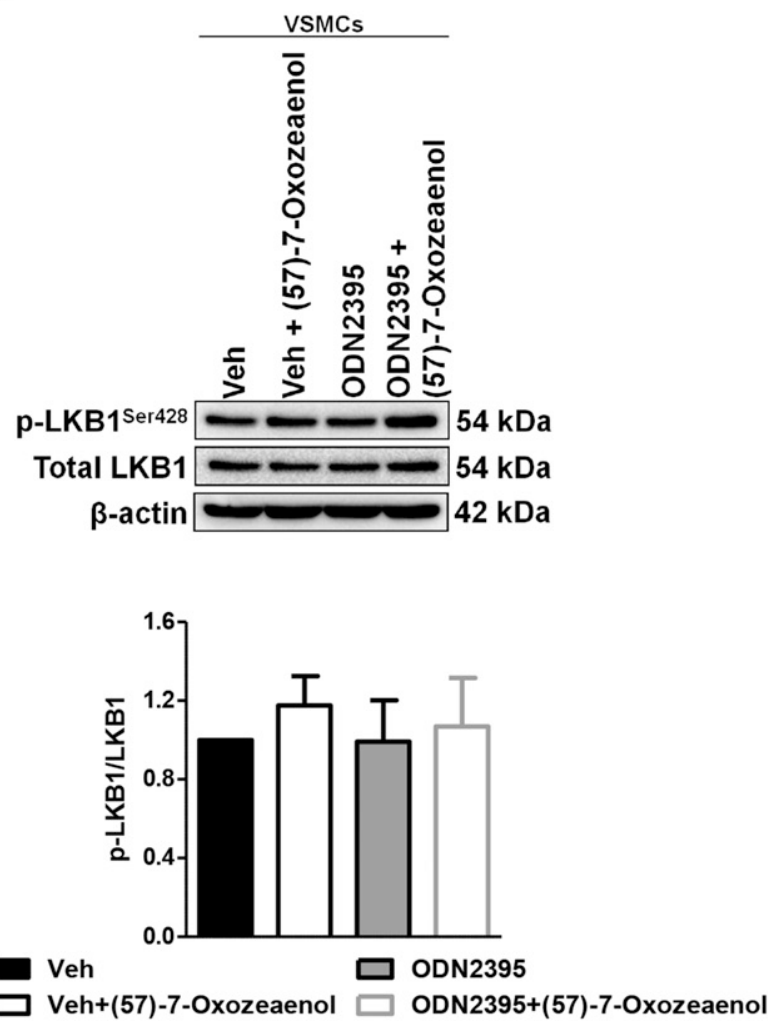

Fig. 3. TLR9 agonist ODN2395-dependent phosphorylation of AMPK $\alpha$ is prevented by inhibiting TAK1 in VSMCs. Protein expression analysis was performed for phospho (p)-AMPK $\alpha^{\text {Thr172 }}$ normalized to total AMPK $\alpha$ after incubation in either vehicle (Veh) or ODN2395 ( $\left.2 \mu \mathrm{mol} / \mathrm{l}\right)$, with and without (57)7-oxozeaenol (100 nmol/l) (A); phospho (p)-TAK1 Thr184/187 normalized to total TAK1 after incubation in either vehicle or ODN2395, with and without ODN2088 $(20 \mu \mathrm{mol} / \mathrm{l})$ (B); phospho-AMPK $\alpha^{\text {Thr172 }}$ normalized to total AMPK $\alpha$ after incubation in either vehicle or ODN2395, with and without bafilomycin A1 (10 nmol/l) (C); and phospho-LKB1 ${ }^{\text {Ser428 }}$ normalized to total LKB1 after incubation in either vehicle or ODN2395, with and without (57)-7-oxozeaenol (D). Above, representative images of immunoblots; below, densitometric analysis. $n=5-8$. One-way ANOVA, $* P<0.05$ vs. vehicle. 


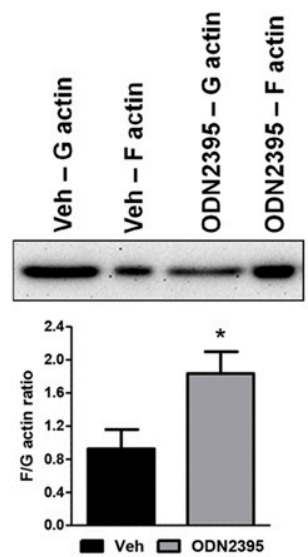

B

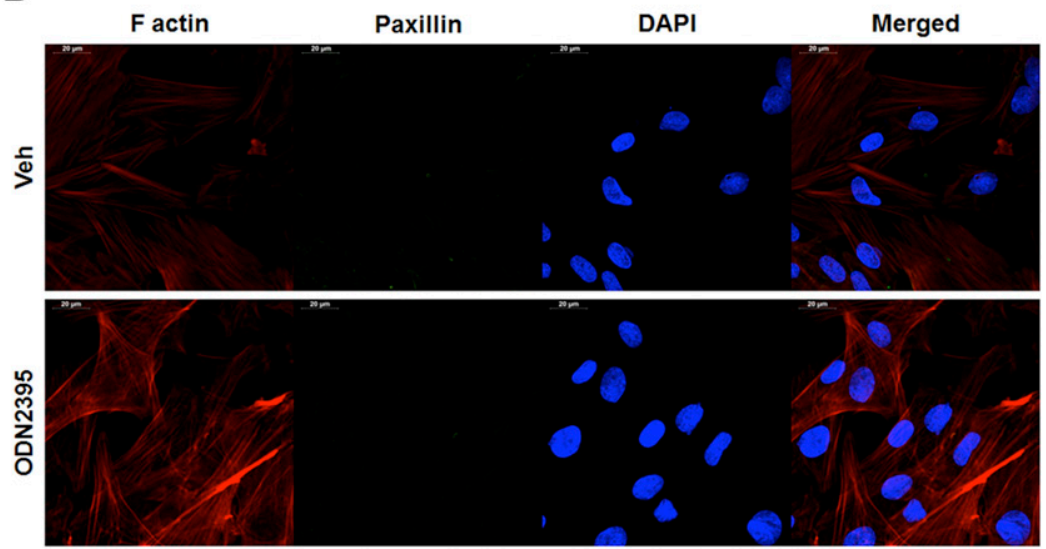

Fig. 4. TLR9 agonist ODN2395 increases the F actin-to-G actin ratio in VSMCs. (A) Quantitative protein expression analysis was performed for $\mathrm{F}$ and $\mathrm{G}$ actin after incubation in either vehicle (Veh) or ODN2395 (2 $\mu \mathrm{mol} / \mathrm{l})$. Above, representative images of immunoblots; below, densitometric analysis. (B) Confocal microscopy $(63 \times$ objective $)$ was also performed to observe $\mathrm{F}$ actin accumulation and organization, as well as immunofluorescence of paxillin, after incubation in either vehicle or ODN2395. $n=4$ to 5 . Student's $t$ test, $* P<0.05$ vs. vehicle. DAPI, $4^{\prime}, 6$-diamidino2-phenylindole. isolated MRA, unlike TLR9 agonist ODN2395. Therefore, an alternative upstream kinase of $\mathrm{AMPK} \alpha$ was investigated. Given that TAK1 has been identified as an activator of AMPK $\alpha$ (Viollet et al., 2010), as well as a kinase involved in canonical TLR9-inflammatory signaling (Vollmer, 2006), it seemed logical that TAK1 was the kinase phosphorylating AMPK $\alpha$ after ODN2395 treatment. TAK1 is a member of the mitogen-activated kinase kinase kinase family (NinomiyaTsuji et al., 2003), and it induces inflammation by activating both p38 and nuclear factor kappa-light-chain-enhancer of activated B cells (NF- $\kappa$ B) (Ninomiya-Tsuji et al., 1999; Sakurai et al., 1999), both of which we have observed in arteries from rats treated with ODN2395 (McCarthy et al., 2015). Moreover, TAK1 also serves as a key regulator of TLR9 signaling in B lymphocytes (Szili et al., 2014) and is also known to regulate AMPK $\alpha$ phosphorylation in cardiac cells (albeit via LKB1, which we did not observe) (Xie et al., 2006) and endothelial cells (Zippel et al., 2013). Therefore, we conclude that the mechanism of $\mathrm{AMPK} \alpha$ phosphorylation after TLR9 activation with ODN2395 in VSMCs is an extension of inflammatory signaling via TAK1 and not the noncanonical stress tolerance signaling cascade.

Why the noncanonical stress tolerance signaling cascade for TLR9 is specialized to cardiomyocytes and neurons and is not conserved across all nonimmune cells is unknown. Physiologically, we hypothesize that one possible reason could be because of the mechanism by which SERCA2 contributes to vascular smooth muscle contraction, which is different from cardiomyocytes. As cardiac contractions are rapid and of short duration, contractile responses are severely diminished after SERCA2 inhibition, illustrating the importance of storeoperated calcium entry to normal cardiac function (MacLennan and Kranias, 2003). On the other hand, vascular smooth muscle contraction is relatively slow, in some cases sustained and tonic, and therefore, inhibition of SERCA2 in vascular smooth muscle promotes contraction by increasing the concentration of calcium that can bind with calmodulin and activate myosin light chain kinase. In turn, calcium, through the process of calcium-induced calcium release, activates the ryanodine receptor, leading to calcium release from the sarcoplasmic reticulum. Unlike cardiomyocytes, where calcium entry is further amplified through calciuminduced calcium release, this process seems to be locally restricted to a few subplasmalemmal calcium sparks sites in VSMCs (Kamishima and Quayle, 2003; House et al., 2008).

Experimentally, we used a type C TLR9 agonist (ODN2395) in the present investigation, whereas Shintani et al. (2013, 2014) used type A and type B ODNs. Type A ODNs induce a strong interferon response but only weakly stimulate $\mathrm{NF}-\kappa \mathrm{B}$, whereas type B ODNs induce a strong NF- $\kappa$ B response but only weakly stimulate interferons (Vollmer and Krieg, 2009). Type C ODNs combine the immunogenicity of both type A and type B ODNs (Vollmer and Krieg, 2009), and also have a complete phosphorothioated backbone, which makes them more resistant to nuclease degradation (Roberts et al., 2011). Based on the combined immunogenicity of ODN2395 and the fact that Shintani et al. $(2013,2014)$ used type A and type B ODNs to support their data, it does not appear that differences 
A

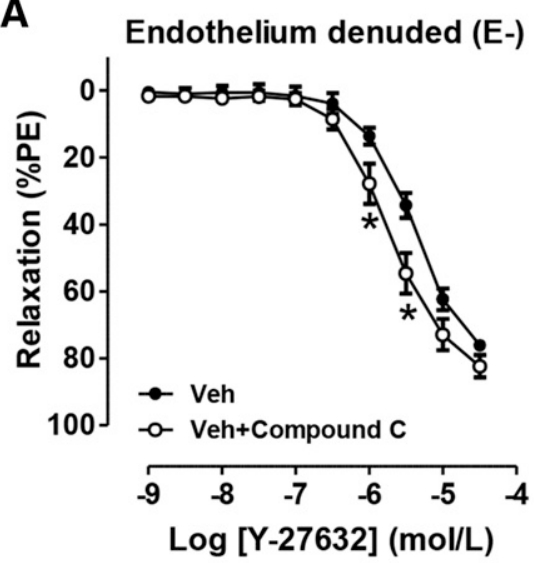

D
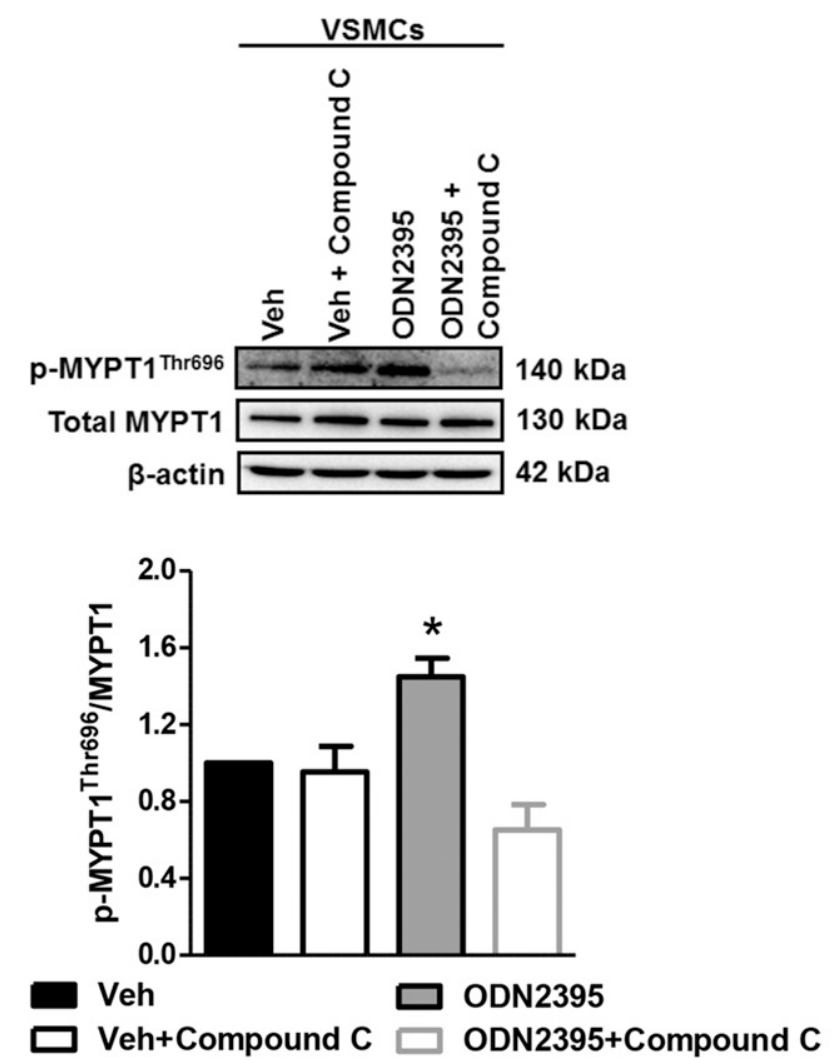

B

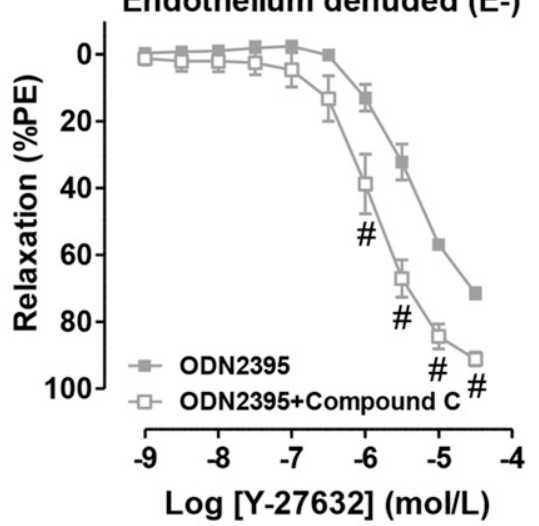

C

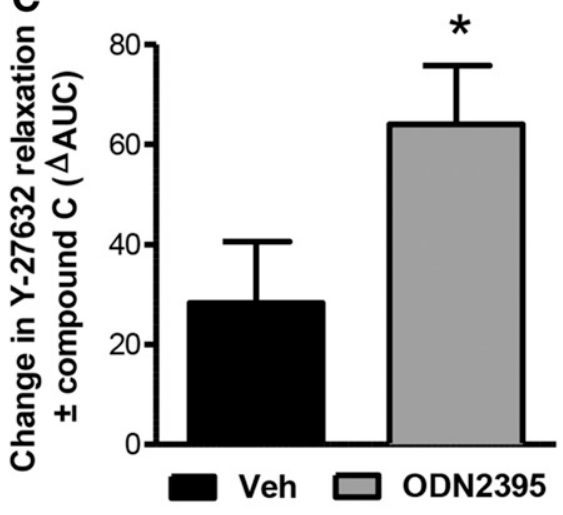

E
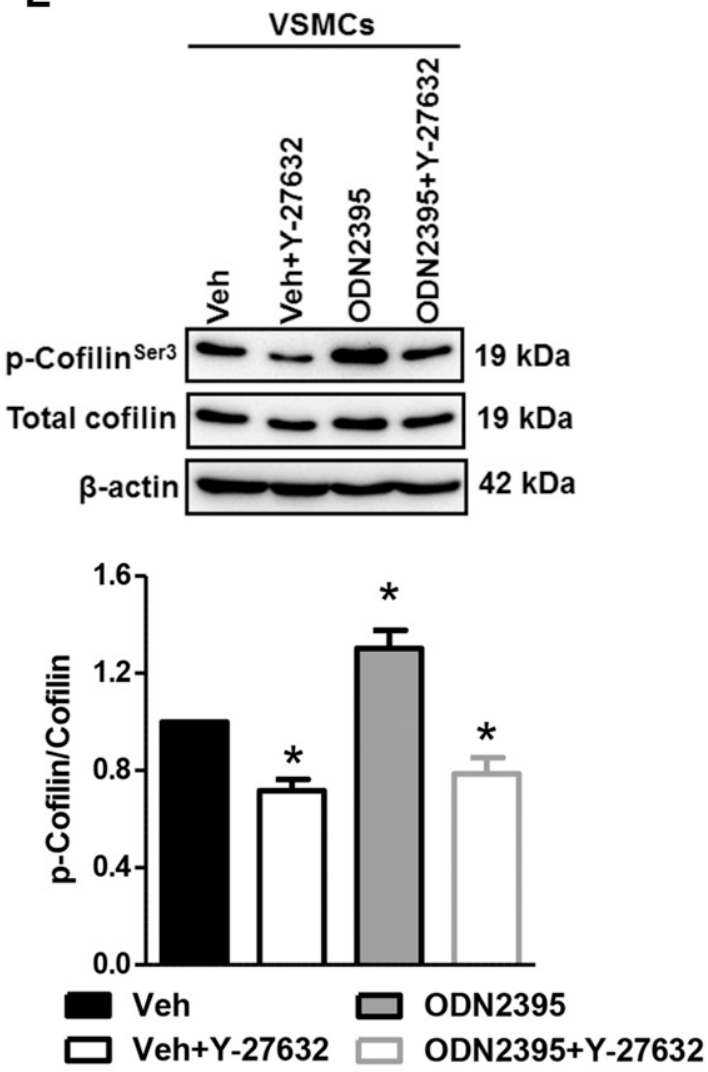

Fig. 5. TLR9 agonist ODN2395 increases RhoA/ROCK activation via AMPK $\alpha$ to regulate actin polymerizing protein cofilin. (A) Concentration-response curves to Y-27632, with or without compound C $(10 \mu \mathrm{mol} / \mathrm{l})$, in denuded (E-) MRAs incubated with vehicle (Veh) or ODN2395 (2 $\mu \mathrm{mol} / \mathrm{l})$. Protein expression analysis for phospho (p)-MYPT1 ${ }^{\text {Thr696 }}$ normalized to total MYPT1 was performed in VSMCs incubated in either vehicle or ODN2395, with and without compound C (B); and phospho (p)-cofilin ${ }^{\text {Ser3 }}$ normalized to total cofilin was performed in VSMCs incubated in either vehicle or ODN2395, with and without Y-27632 $(1 \mu \mathrm{mol} / \mathrm{l})(\mathrm{C})$. Above, representative images of immunoblots; below, densitometric analysis. $n=4$ to 5 . Two-way ANOVA, ${ }^{*} P<$ 0.05 vs. vehicle, $\# P<0.05$ vs. ODN2395; Student's $t$ test, $* P<0.05$ vs. vehicle; one-way ANOVA, $* P<0.05$ vs. vehicle.

in TLR9 agonist choice explains the confounding data between the two studies.

Similarly, we also acknowledge the temporal differences of AMPK $\alpha$ phosphorylation (Thr172) between our study and those of Shintani et al. (2013, 2014). In cardiomyocytes, Shintani et al. (2013, 2014) observed increases in phosphoAMPK $\alpha^{\text {Thr172 }}$ as early as 10 minutes after TLR9 activation. Nonetheless, this increase only reached statistical significance at the 30-, 60- (peak phosphorylation), and 120-minute time points. In our previous publication (McCarthy et al., 2015), we observed significant increases in phosphoAMPK $\alpha^{\text {Thr172 }}$ at 15 and 30 minutes after TLR9 activation in isolated MRAs. Based on these data, 20 minutes was chosen as a single time point in the present study. It does not appear that we missed activation of the noncanonical stress tolerance signaling cascade for TLR9 because our luciferase assay incorporated a time course $(5,10,20,40$, and 60 minutes); and no difference in ATP concentration, and thus SERCA2 


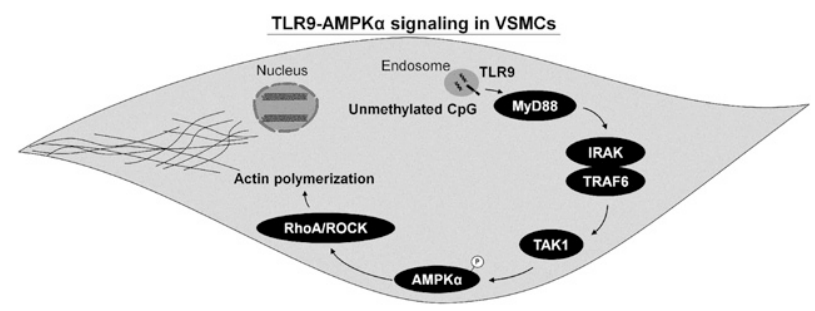

Fig. 6. Schematic summarizing TLR9-AMPK $\alpha$ signaling in VSMCs. TLR9 activation in VSMCs leads to the phosphorylation of AMPK $\alpha$ via TAK1, and activated AMPK $\alpha$ can subsequently trigger RhoA/ROCK, mediating the accumulation and disorganization of $\mathrm{F}$ actin. IRAK, interleukin-1 receptor-associated kinase.

activity, was observed between vehicle- and ODN2395-treated microsomes.

Regardless of its mechanism of activation, AMPK $\alpha$ is recognized to have multiple effects on vascular function (Salt and Hardie, 2017). As a serine-threonine kinase protein complex that is a central regulator of cellular energy homeostasis, there is an abundance of literature demonstrating that $\operatorname{AMPK} \alpha$ has anticontractile-prorelaxant properties (Ewart and Kennedy, 2011; Garcia-Prieto et al., 2015), including phosphorylation of endothelial nitric oxide synthase (eNOS) at the activation site serine 1177 (Chen et al., 1999; Morrow et al., 2003) as well as mechanisms that are independent of the endothelium (Horman et al., 2008; Davis et al., 2012; Sung and Choi, 2012; Pyla et al., 2014). However, there are instances when AMPK induces vascular dysfunction (Turkseven and Ertuna, 2013), and AMPK $\alpha$ is also known to phosphorylate eNOS at threonine 495 in the calcium-calmodulin-binding sequence, resulting in the inhibition of eNOS activity (Chen et al., 1999). Given the clear phosphorylation of AMPK $\alpha$ (Thr172), in conjunction with heightened contractile responses we previously reported in rats treated with ODN2395 (McCarthy et al., 2015), and our original focus in the current manuscript on vascular smooth muscle contraction, we hypothesized that TLR9-AMPK $\alpha$ signaling may be mediating actin cytoskeleton reorganization (Zheng and Cantley, 2007; Miranda et al., 2010), particularly in vascular smooth muscle. Nonetheless, it is interesting to postulate why TLR9-dependent activation of AMPK $\alpha$ abrogates its positive effects on vascular function, particularly in conditions when the endothelium is present, such as our in vivo model (McCarthy et al., 2015). In addition to the potential for cytoskeleton reorganization in endothelial cells (thus impairing the barrier function of the endothelium), we also hypothesize that the concurrent generations of reactive oxygen species and/or proinflammatory cytokines downstream of TLR9 are causing AMPK $\alpha$ to become dysregulated. Specific experiments will be required to test these hypotheses in future studies.

It is well known that RhoA through serine-threonine kinase ROCK mediates VSMC function by calcium sensitization (maintaining the activity of myosin light-chain kinase, independently of free cytosolic calcium) and cytoskeleton reorganization (Nunes et al., 2010). In our vascular reactivity experiments, precontraction to $\alpha_{1}$-adrenergic agonists was not different in arteries incubated with vehicle or ODN2395 (data not shown), and, surprisingly, the magnitude of relaxation to Y-27632 was not different between vehicle and ODN2395. Therefore, we can infer that the potentiated relaxation of denuded MRA to Y-27632 after incubation with ODN2395 and compound $\mathrm{C}$ is due to a decrease in $\mathrm{F}$ actin formation, as opposed to an inhibition of calcium sensitization and contractility.

In this investigation, we observed that $\mathrm{AMPK} \alpha$ can activate RhoA/ROCK signaling in VSMCs, similar to what has been observed in kidney epithelial cells (Miranda et al., 2010). It is well established that the Rho family GTPases are key regulators of cytoskeleton organization, with the GTPase RhoA controlling stress fiber formation and actin polymerization (Hall, 1998). ROCK interacts with RhoA, and the two substrates of this kinase, myosin light chain phosphatase and myosin light chain, can regulate the assembly of actin-myosin filament bundles (Hall, 1998). Although ROCK does not directly phosphorylate the actin-severing protein cofilin, it is able to phosphorylate LIM-kinase, which in turn phosphorylates and inactivates cofilin (Maekawa et al., 1999) and thus promotes the stabilization and accumulation of $\mathrm{F}$ actin (Moon and Drubin, 1995), which is what we observed in our study. Overall, these data add to the growing body of literature, suggesting that ROCK can be activated via mechanisms other than Rho guanine nucleotide exchange factors (Boulter et al., 2012).

In conclusion, the current investigation reveals a novel mechanism by which TLR9 contributes to the pathogenesis of cardiovascular diseases (McCarthy et al., 2014; Goulopoulou et al., 2016). Although this mechanism did not involve changes in calcium handling via SERCA2 inhibition like originally hypothesized, it did involve modulating actin cytoskeleton organization, which could then contribute to reduced vasodilation and decreased blood flow to end organs. These data further emphasize the far-reaching effects of immune system activation in (patho)physiology, especially in tissues, which in many cases, are the first to respond to perturbations in homeostasis (Matzinger and Kamala, 2011).

\section{Authorship Contributions}

Participated in research design: McCarthy, Wenceslau, Szasz, and Webb.

Conducted experiments: McCarthy, Wenceslau, and Ogbi.

Performed data analysis: McCarthy.

Wrote or contributed to the writing of the manuscript: McCarthy, Wenceslau, Szasz, and Webb.

\section{References}

Bomfim GF, Rodrigues FL, and Carneiro FS (2017) Are the innate and adaptive immune systems setting hypertension on fire? Pharmacol Res 117:377-393.

Boulter E, Estrach S, Garcia-Mata R, and Féral CC (2012) Off the beaten paths: alternative and crosstalk regulation of Rho GTPases. FASEB J 26:469-479.

Chen ZP, Mitchelhill KI, Michell BJ, Stapleton D, Rodriguez-Crespo I, Witters LA, Power DA, Ortiz de Montellano PR, and Kemp BE (1999) AMP-activated protein kinase phosphorylation of endothelial NO synthase. FEBS Lett 443:285-289.

Chockalingam A, Brooks JC, Cameron JL, Blum LK, and Leifer CA (2009) TLR9 traffics through the golgi complex to localize to endolysosomes and respond to $\mathrm{CpG}$ DNA. Immunol Cell Biol 87:209-217.

Davis B, Rahman A, and Arner A (2012) AMP-activated kinase relaxes agonist induced contractions in the mouse aorta via effects on PKC signaling and inhibits NO-induced relaxation. Eur J Pharmacol 695:88-95.

Ewart MA and Kennedy S (2011) AMPK and vasculoprotection. Pharmacol Ther 131: 242-253.

García-Prieto CF, Gil-Ortega M, Aránguez I, Ortiz-Besoain M, Somoza B, and Fernández-Alfonso MS (2015) Vascular AMPK as an attractive target in the treatment of vascular complications of obesity. Vascul Pharmacol 67-69:10-20.

Giachini FR, Chiao CW, Carneiro FS, Lima VV, Carneiro ZN, Dorrance AM, Tostes RC, and Webb RC (2009) Increased activation of stromal interaction molecule-1/ Orai-1 in aorta from hypertensive rats: a novel insight into vascular dysfunction. Hypertension 53:409-416.

Goulopoulou S, McCarthy CG, and Webb RC (2016) Toll-like receptors in the vascular system: sensing the dangers within. Pharmacol Rev 68:142-167.

Hall A (1998) Rho GTPases and the actin cytoskeleton. Science 279:509-514. 
Horman S, Morel N, Vertommen D, Hussain N, Neumann D, Beauloye C, El Najjar N, Forcet C, Viollet B, Walsh MP, et al. (2008) AMP-activated protein kinase phosphorylates and desensitizes smooth muscle myosin light chain kinase. J Biol Chem 283:18505-18512.

House SJ, Potier M, Bisaillon J, Singer HA, and Trebak M (2008) The non-excitable smooth muscle: calcium signaling and phenotypic switching during vascular disease. Pflugers Arch 456:769-785.

Kamishima T and Quayle JM (2003) Ca2+-induced $\mathrm{Ca} 2+$ release in cardiac and smooth muscle cells. Biochem Soc Trans 31:943-946.

Klinman DM (2004) Immunotherapeutic uses of CpG oligodeoxynucleotides. Nat Rev Immunol 4:249-258.

Latz E, Schoenemeyer A, Visintin A, Fitzgerald KA, Monks BG, Knetter CF, Lien E, Nilsen NJ, Espevik T, and Golenbock DT (2004) TLR9 signals after translocating from the ER to CpG DNA in the lysosome. Nat Immunol 5:190-198.

Leifer CA, Kennedy MN, Mazzoni A, Lee C, Kruhlak MJ, and Segal DM (2004) TLR9 is localized in the endoplasmic reticulum prior to stimulation. J Immunol 173:1179-1183.

MacLennan DH and Kranias EG (2003) Phospholamban: a crucial regulator of cardiac contractility. Nat Rev Mol Cell Biol 4:566-577.

Maekawa M, Ishizaki T, Boku S, Watanabe N, Fujita A, Iwamatsu A, Obinata T, Ohashi K, Mizuno K, and Narumiya S (1999) Signaling from Rho to the actin cytoskeleton through protein kinases ROCK and LIM-kinase. Science 285:895-898.

Matzinger P and Kamala T (2011) Tissue-based class control: the other side of tolerance. Nat Rev Immunol 11:221-230.

McCarthy CG, Goulopoulou S, Wenceslau CF, Spitler K, Matsumoto T, and Webb RC (2014) Toll-like receptors and damage-associated molecular patterns: novel links between inflammation and hypertension. Am J Physiol Heart Circ Physiol 306: H184-H196.

McCarthy CG, Wenceslau CF, Goulopoulou S, Ogbi S, Baban B, Sullivan JC, Matsumoto T, and Webb RC (2015) Circulating mitochondrial DNA and Toll-like receptor 9 are associated with vascular dysfunction in spontaneously hypertensive rats. Cardiovasc Res 107:119-130.

McGuire PG, Walker-Caprioglio HM, Little SA, and McGuffee LJ (1993) Isolation and culture of rat superior mesenteric artery smooth muscle cells. In Vitro Cell Dev Biol 29A:135-139.

Miranda L, Carpentier S, Platek A, Hussain N, Gueuning MA, Vertommen D, Ozkan Y, Sid B, Hue L, Courtoy PJ, et al. (2010) AMP-activated protein kinase induces actin cytoskeleton reorganization in epithelial cells. Biochem Biophys Res Commun 396:656-661.

Momcilovic M, Hong SP, and Carlson M (2006) Mammalian TAK1 activates Snf1 protein kinase in yeast and phosphorylates AMP-activated protein kinase in vitro. J Biol Chem 281:25336-25343.

Moon A and Drubin DG (1995) The ADF/cofilin proteins: stimulus-responsive modulators of actin dynamics. Mol Biol Cell 6:1423-1431.

Morrow VA, Foufelle F, Connell JM, Petrie JR, Gould GW, and Salt IP (2003) Direct activation of AMP-activated protein kinase stimulates nitric-oxide synthesis in human aortic endothelial cells. J Biol Chem 278:31629-31639.

Ninomiya-Tsuji J, Kajino T, Ono K, Ohtomo T, Matsumoto M, Shiina M, Mihara M, Tsuchiya M, and Matsumoto K (2003) A resorcylic acid lactone, 5Z-7-oxozeaenol, prevents inflammation by inhibiting the catalytic activity of TAK1 MAPK kinase kinase. J Biol Chem 278:18485-18490.

Ninomiya-Tsuji J, Kishimoto K, Hiyama A, Inoue J, Cao Z, and Matsumoto K (1999) The kinase TAK1 can activate the NIK-I kappaB as well as the MAP kinase cascade in the IL-1 signalling pathway. Nature 398:252-256.

Nunes KP, Rigsby CS, and Webb RC (2010) RhoA/Rho-kinase and vascular diseases: what is the link? Cell Mol Life Sci 67:3823-3836.

Oka T, Hikoso S, Yamaguchi O, Taneike M, Takeda T, Tamai T, Oyabu J, Murakawa T, Nakayama H, Nishida K, et al. (2012) Mitochondrial DNA that escapes from autophagy causes inflammation and heart failure. Nature 485:251-255.

Pyla R, Osman I, Pichavaram P, Hansen P, and Segar L (2014) Metformin exaggerates phenylephrine-induced AMPK phosphorylation independent of CaMKK $\beta$ and attenuates contractile response in endothelium-denuded rat aorta. Biochem Pharmacol 92:266-279.
Roberts TL, Dunn JA, Sweet MJ, Hume DA, and Stacey KJ (2011) The immunostimulatory activity of phosphorothioate $\mathrm{CpG}$ oligonucleotides is affected by distal sequence changes. Mol Immunol 48:1027-1034.

Sakurai H, Miyoshi H, Toriumi W, and Sugita T (1999) Functional interactions of transforming growth factor beta-activated kinase 1 with IkappaB kinases to stimulate NF-kappaB activation. J Biol Chem 274:10641-10648.

Salt IP and Hardie DG (2017) AMP-activated protein kinase: an ubiquitous signaling pathway with key roles in the cardiovascular system. Circ Res 120:1825-1841.

Shintani Y, Drexler HC, Kioka H, Terracciano CM, Coppen SR, Imamura H, Akao M, Nakai J, Wheeler AP, Higo S, et al. (2014) Toll-like receptor 9 protects non-immune cells from stress by modulating mitochondrial ATP synthesis through the inhibition of SERCA2. EMBO Rep 15:438-445.

Shintani Y, Kapoor A, Kaneko M, Smolenski RT, D’Acquisto F, Coppen SR, HaradaShoji N, Lee HJ, Thiemermann C, Takashima S, et al. (2013) TLR9 mediates cellular protection by modulating energy metabolism in cardiomyocytes and neurons. Proc Natl Acad Sci USA 110:5109-5114.

Stacey KJ, Young GR, Clark F, Sester DP, Roberts TL, Naik S, Sweet MJ, and Hume DA (2003) The molecular basis for the lack of immunostimulatory activity of vertebrate DNA. J Immunol 170:3614-3620.

Sung JY and Choi HC (2012) Metformin-induced AMP-activated protein kinase activation regulates phenylephrine-mediated contraction of rat aorta. Biochem Biophys Res Commun 421:599-604.

Szili D, Bankó Z, Tóth EA, Nagy G, Rojkovich B, Gáti T, Simon M, Hérincs Z, and Sármay G (2014) TGF $\beta$ activated kinase 1 (TAK1) at the crossroad of B cell receptor and Toll-like receptor 9 signaling pathways in human B cells. PLoS One $\mathbf{9}$ e96381.

Tostes RC, Traub O, Bendhack LM, and Webb RC (1995) Sarcoplasmic reticulum $\mathrm{Ca}^{2+}$ uptake is not decreased in aorta from deoxycorticosterone acetate hypertensive rats: functional assessment with cyclopiazonic acid. Can J Physiol Pharmacol 73:1536-1545.

Turkseven S and Ertuna E (2013) Prolonged AMP-activated protein kinase induction impairs vascular functions. Can J Physiol Pharmacol 91:1025-1030.

Veǐko NN, Konorova IL, Neverova ME, Fidelina OV, Mkrtumova NA, Ershova ES, Kon'kova MS, and Postnov AIu (2010) Delayed appearance of hypertension in spontaneously hypertensive rat (SHR) injected with CpG-rich DNA early in ontogenesis. Biomed Khim 56:686-699.

Viollet B, Horman S, Leclerc J, Lantier L, Foretz M, Billaud M, Giri S, and Andreelli F (2010) AMPK inhibition in health and disease. Crit Rev Biochem Mol Biol 45: 276-295.

Vollmer J (2006) TLR9 in health and disease. Int Rev Immunol 25:155-181.

Vollmer J and Krieg AM (2009) Immunotherapeutic applications of CpG oligodeoxynucleotide TLR9 agonists. Adv Drug Deliv Rev 61:195-204.

Webb RC and Bhalla RC (1976) Calcium sequestration by subcellular fractions isolated from vascular smooth muscle: effect of cyclic nucleotides and prostaglandins. J Mol Cell Cardiol 8:145-157.

Xie M, Zhang D, Dyck JR, Li Y, Zhang H, Morishima M, Mann DL, Taffet GE, Baldini A, Khoury DS, et al. (2006) A pivotal role for endogenous TGF-beta-activated kinase-1 in the LKB1/AMP-activated protein kinase energy-sensor pathway. Proc Natl Acad Sci USA 103:17378-17383.

Zheng B and Cantley LC (2007) Regulation of epithelial tight junction assembly and disassembly by AMP-activated protein kinase. Proc Natl Acad Sci USA 104: 819-822.

Zippel N, Malik RA, Frömel T, Popp R, Bess E, Strilic B, Wettschureck N, Fleming I, and Fisslthaler B (2013) Transforming growth factor- $\beta$-activated kinase 1 regulates angiogenesis via AMP-activated protein kinase- $\alpha 1$ and redox balance in endothelial cells. Arterioscler Thromb Vasc Biol 33:2792-2799.

Address correspondence to: Cameron G. McCarthy, Department of Physiology, Augusta University, 1120 15th Street, Augusta, GA 30912. E-mail: cmccarthy@augusta.edu 